\title{
Acidez do solo afetando concentração de micronutrientes, atividade da enzima nitrato redutase e produtividade em plantas de arroz de terras altas
}

\author{
Soil acidity as affecting micronutrients concentration, nitrato \\ reductase enzyme activity and yield in upland rice plants
}

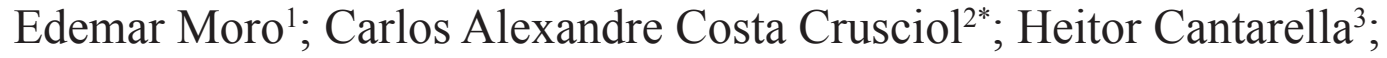 \\ Adriano Stephan Nascente ${ }^{4}$; Adriana Lima Moro ${ }^{1}$; Fernando Broetto ${ }^{5}$
}

\section{Resumo}

\begin{abstract}
A menor produtividade grãos de arroz no sistema plantio direto (SPD) em relação ao sistema convencional pode ser devido ao predomínio de nitrato no solo e da baixa atividade da nitrato redutase. Um outra causa pode ser a deficiência por micronutrientes causada pelas correções superficiais da acidez do solo. Assim, o objetivo desse estudo foi de avaliar as alterações que o $\mathrm{pH}$ do solo provoca nas formas de $\mathrm{N}$ do solo, no teor de micronutrientes das plantas de arroz, na atividade da enzima nitrato redutase, nos componentes de produção e produtividade do arroz. O experimento foi conduzido em casa de vegetação. $\mathrm{O}$ delineamento experimental foi inteiramente casualizado no esquema fatorial três (níveis de acidez) x cinco (fontes de micronutrientes), com quatro repetições. A adição de micronutrientes não afeta os teores de amônio e nitrato no solo; a acidez do solo afeta significativamente os teores de nitrato e amônio no solo, os teores de micronutrientes pelas plantas de arroz, a produtividade da cultura e os componentes de produção; a acidez média do solo ( $\mathrm{pH}$ 5,5) propicia teores médios a altos de $\mathrm{Cu}$ e $\mathrm{Fe}$, médios de $\mathrm{Zn}$ e Mn, alta atividade da enzima NR, resultando em maiores valores de matéria seca, perfilhos, panículas, espiguetas, peso de 100 grãos e consequentemente produtividade de grãos.

Palavras-chave: Oryza sativa, fertilidade do solo, acidez do solo, produtividade, sistema plantio direto
\end{abstract}

\begin{abstract}
The lowest grain yield of rice under no-tillage system (NTS) in relation to the conventional system may be due to the predominance nitrate in the soil and the low nitrate reductase activity. Another reason may be caused by micronutrient deficiency because of superficially soil acidity corrections. Therefore, the objective of this study was to evaluate the changes caused by soil $\mathrm{pH}$ in the $\mathrm{N}$ forms in the soil, micronutrients concentration in rice plants, nitrate reductase activity, yield of rice and its components. The experiment was performed in a greenhouse conditions. The experimental design was a completely randomized in a factorial three (levels of soil acidity) x five (micronutrients sources) with four replications. The addition of micronutrients does not affect levels of nitrate and ammonium
\end{abstract}

${ }^{1}$ Eng $^{\text {os }}$ Agr ${ }^{\text {os }}$, Profs. Drs. da Universidade do Oeste Paulista, UNOESTE, Faculdade de Ciências Agrárias, Presidente Prudente, SP. E-mail: edemar@unoeste.br; adrianamoro@unoeste.br

${ }^{2}$ Eng $^{\circ}$ Agr $^{\circ}$, Prof. Titular, Dr. do Dept ${ }^{\circ}$ de Produção Vegetal, Universidade Estadual Paulista, UNESP, Faculdade de Ciências Agronômicas, FCA, Botucatu, SP. Bolsista do CNPq. E-mail: crusciol@fca.unesp.br

${ }^{3}$ Eng $^{\circ}$ Agr $^{\circ}$, Pesquisador VI, Dr. do Instituto Agronômico de Campinas, IAC, Centro de Solos e Recursos Ambientais, Campinas, SP. Bolsista do CNPq. E-mail: cantarella@iac.sp.gov.br

${ }^{4}$ Eng $^{\circ}$ Agr $^{\circ}$, Pesquisador, Dr. Embrapa Arroz e Feijão, Santo Antônio de Goiás, GO. E-mail: adriano.nascente@embrapa.br

${ }^{5}$ Eng $^{\text {o }}$ Agr $^{0}$, Prof. Adjunto, Dr. do Dept ${ }^{\circ}$ de Química e Bioquímica, UNESP, Instituto de Biociências, Botucatu, SP. Bolsista do CNPq. E-mail: broetto@ibb.unesp.br

* Autor para correspondência

Recebido para publicação 17/07/12 Aprovado em 06/11/12 
in the soil; soil acidity significantly affects levels of nitrate and ammonium in the soil, concentration of micronutrients in rice plants and crop yield and its components; medium soil acidity ( $\mathrm{pH} 5.5$ ) result in medium to high levels of $\mathrm{Cu}$ and $\mathrm{Fe}$, medium level of $\mathrm{Zn}$ and $\mathrm{Mn}$, high nitrate reductase activity, resulting in higher dry matter, tillers, panicles, spikelets, weight of 100 grains and hence grain yield.

Key words: Oryza sativa, soil fertility, soil acidity, yield, no-tillage system

\section{Introdução}

Em razão da redução da água disponível para a produção irrigada do arroz na Ásia, causada pelo aumento da demanda pelas indústrias e população, torna-se necessário o desenvolvimento de alternativas viáveis que possibilitem o aumento da produção com uso de forma racional desse recurso natural (BOUMAN et al., 2007). Umas das alternativas seria a produção do arroz no sistema plantio direto (SPD), cultivado em condições aeróbicas, caracterizado pela maior conservação da umidade do solo em relação ao sistema convencional (KLUTHCOUSKI et al., 2000; MAUAD; CRUSCIOL; GRASSI FILHO, 2011; NASCENTE et al., 2011a, 2011b).

A utilização do arroz de terras altas nesse sistema ainda necessita de ajustes, pois a cultura não tem tido adequado desenvolvimento no SPD (KLUTHCOUSKI et al., 2000; CRUSCIOL et al., 2010; NASCENTE et al., 2012). Umas das razões seria a baixa capacidade de assimilação do nitrato pelas plântulas de arroz, devido à baixa atividade da enzima nitrato redutase (MALAVOLTA, 1980). D'Andréa et al. (2004) relataram que no SPD há maior disponibilidade de $\mathrm{N}_{-} \mathrm{NO}_{3}^{-}$no solo em relação ao sistema convencional de preparo do solo. Isso ocorre porque no ambiente em SPD devido à umidade, teor de nutrientes e maiores quantidades de matéria orgânica há maior atividade microbiológica, em especial das bactérias nitrificadoras (ARAÚJO, 2005). Araújo (2005) relatou que o arroz teve melhor desenvolvimento quando havia maiores quantidade de nitrogênio no solo na forma de

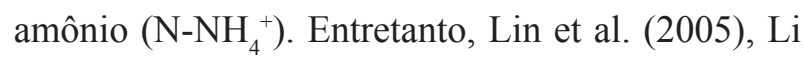
et al. (2007) e Poletto et al. (2011) ressaltam que somente amônio pode ser prejudicial ao arroz.
A nitrato redutase é a enzima responsável pela

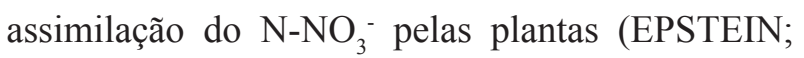
BLOOM, 2006; SANTOS et al., 2009). Neste contexto, o arroz, por ser uma planta hidrófila de ambiente reduzido, com predominância do nitrogênio na forma de amônio, tem dificuldade de sintetizar no primeiro mês de desenvolvimento a enzima nitrato redutase, o que pode explicar o baixo desenvolvimento inicial da cultura (MALAVOLTA, 1980).

Adicionalmente, no SPD devido a correção superficial da acidez, pode acarretar em diminuição no teor de alguns micronutrientes, principalmente os catiônicos ( $\mathrm{Cu}, \mathrm{Mn}, \mathrm{Zn}$ e $\mathrm{Fe}$ ) (FAGERIA, 2000). Soratto e Crusciol (2008) observaram que a elevação do $\mathrm{pH}$ afetou a disponibilidade de manganês para a cultura do arroz. Fageria (2000) verificou redução na disponibilidade de $\mathrm{Fe}$, o que poderia comprometer a conversão do $\mathrm{NO}_{3}{ }^{-}$a $\mathrm{NO}_{2}{ }^{-}$ , visto que o $\mathrm{Fe}$ é essencial à redução do nitrato (MALAVOLTA, 1980; TISDALE; NELSON; BEATON, 1985).

Em função do relato acima, realizou-se o presente trabalho com objetivo de avaliar as alterações que o $\mathrm{pH}$ do solo provocam nas formas de $\mathrm{N}$ mineral do solo, na atividade da enzima nitrato redutase e nos teores de micronutrientes no arroz, bem como na produtividade de grãos da cultura e seus componentes.

\section{Material e Métodos}

$\mathrm{O}$ experimento foi conduzido em casa de vegetação em Botucatu-SP. Foi utilizado solo proveniente da camada arável $(0-20 \mathrm{~cm})$ de um Latossolo Vermelho eutrófico cultivado sob 
SPD já consolidado (seis anos). A seqüência de culturas neste período foi: 1 . soja/aveia preta, 2. milho/Brachiaria brizantha, 3. milho/Brachiaria brizantha, 4. soja/aveia branca, 5. feijão/aveia branca, e 6. soja/pousio. O solo coletado foi dividido em três porções iguais. Uma das porções foi mantida com o $\mathrm{pH}$ original $(4,5)$ e nas outras duas procedeuse a elevação do $\mathrm{pH}$ à 5,5 e a 6,3. Para a elevação do $\mathrm{pH}$ aos valores propostos foi utilizado $\mathrm{CaCO}_{3}+$ $\mathrm{MgCO}_{3}$ p.a., sendo que, a quantidade utilizada foi determinada pelo método de incubação (30 dias) (RAIJ et al., 2001). As quantidades determinadas de calcário foram aplicadas nas porções de solo, as quais permaneceram em incubação durante 30 dias, com umidade na capacidade máxima de retenção de água do solo para reação do corretivo. As características químicas foram avaliadas antes e após a incubação de 30 dias, seguindo metodologia proposta por Raij et al. (2001) (Tabela 1). O solo foi retirado dos vasos, secado à sombra e cada porção de solo foi adubada com $150 \mathrm{mg} \mathrm{dm}^{-3}$ de P e 80 $\mathrm{mg} \mathrm{dm^{-3 }}$ de $\mathrm{K}$, nas formas de superfosfato triplo e cloreto de potássio, respectivamente (RAIJ et al., 1996).

Tabela 1. Atributos químicos do solo antes da incubação com calcário e 30 dias após. Botucatu-SP, 2009.

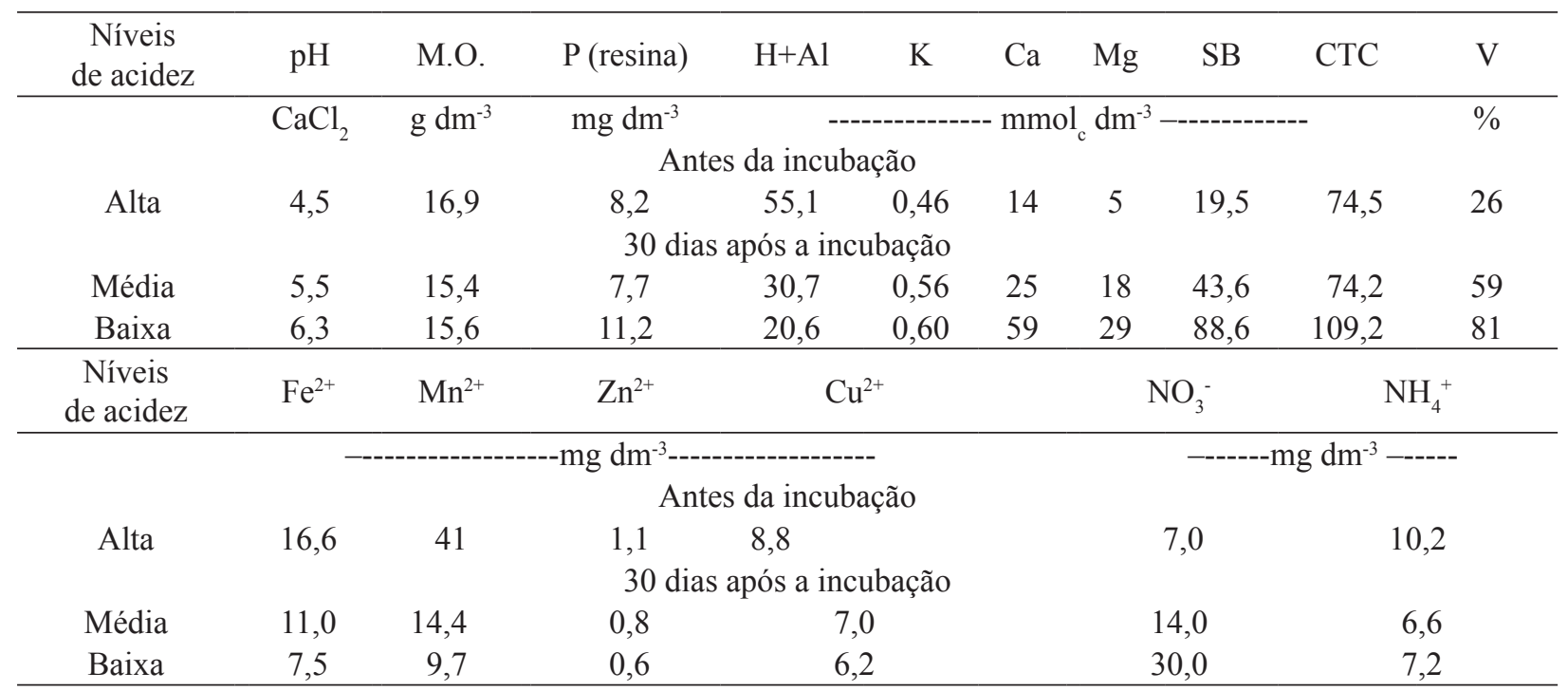

Fonte: Elaboração dos autores.

Assim, o delineamento experimental foi inteiramente casualizados no esquema fatorial $3 \times 5$, com quatro repetições. $\mathrm{O}$ experimento foi constituído por três níveis de acidez $\left(\mathrm{pH} \mathrm{CaCl}_{2}\right)$ do solo (alta $-\mathrm{pH}=4,5$, média $-\mathrm{pH}=5,5$ e baixa $-\mathrm{pH}$ $=6,3)$ e quatro tratamentos com micronutrientes ( 1 $-\mathrm{Zn}, 2-\mathrm{Fe}, 3-\mathrm{Mn}, 4-\mathrm{Zn}+\mathrm{Fe}+\mathrm{Mn}$ (COQUETEL) e 5 - controle (ausência de micronutrientes)). Os micronutrientes foram fornecidos nas seguintes fontes e doses: $\mathrm{Zn}-\mathrm{ZnSO}_{4} 10 \mathrm{mg} \mathrm{dm}{ }^{-3}$, Fe-ferrilene (EDDHA 6\%) $10 \mathrm{mg} \mathrm{dm}{ }^{-3}, \mathrm{Mn}^{-} \mathrm{MnSO}_{4} 3 \mathrm{mg} \mathrm{dm}{ }^{-3}$ e $\mathrm{Zn}+\mathrm{Fe}+\mathrm{Mn}$ (foram fornecidos na mesma fonte e dose dos tratamentos individuais) (RAIJ et al., 1996). As unidades experimentais foram constituídas por vasos plásticos totalmente preenchidos com solo, com capacidade para $17 \mathrm{~kg}$. Foram alocadas 20 sementes de arroz por vaso (cultivar IAC-202) e após a germinação foram mantidas 10 plantas.

A adubação de cobertura foi realizada com nitrato de amônio $\left(\mathrm{NH}_{4} \mathrm{NO}_{3}\right)$, utilizando-se $80 \mathrm{mg}$ $\mathrm{dm}^{-3}$, e parcelada em duas épocas, sendo metade imediatamente após a emergência do arroz e o restante aos 15 dias após a primeira. A umidade do solo durante todo o experimento teve monitoramento 
diário, por meio de pesagem dos vasos, sendo que a reposição da água evapotranspirada ocorria quando essa atingia $85 \%$, elevando a $100 \%$ da capacidade de campo.

A amostragem de solo e de plantas foi realizada em todas unidades experimentais aos 7, 14, $21 \mathrm{e}$ 28 dias após a emergência (DAE), sendo o solo mantido a $-20^{\circ} \mathrm{C}$, até o momento da análise. As amostras de solo foram retiradas na profundidade de $0-20 \mathrm{~cm}$ com auxilio de trado calador em todas as unidades experimentais. Os teores de $\mathrm{NO}_{3}{ }^{-}$e $\mathrm{NH}_{4}^{+}$ no solo foram determinados pelo método proposto por Silva (1999) e o teor de micronutrientes na parte aérea foi determinado de acordo com Malavolta, Vitti e Oliveira (1997), sendo coletado uma planta inteira por vaso a cada avaliação. Com relação a avaliação da atividade da NR, a coleta das folhas foi realizada no período da manhã entre às 8:00 e às 10:00 horas. Foi coletada a primeira folha recém expandida abaixo da folha bandeira por vaso e colocada em tubos de Falcon (50 mL) e congeladas em nitrogênio líquido. Durante a coleta, as folhas já congeladas foram mantidas em caixas de isopor com nitrogênio líquido. Posteriormente o material coletado foi armazenado em freezer a $-80^{\circ} \mathrm{C}$ até o momento de determinação da atividade da enzima nitrato redutase (JAWORSKI, 1971).

Assim, para avaliar a atividade da NR pesou-se $200 \mathrm{mg}$ de tecido foliar (provenientes do terço médio da folha). A matéria fresca pesada foi colocada em tubos de ensaio com $5 \mathrm{~mL}$ de solução de incubação. Está solução foi constituída por tampão fosfato $\left(\mathrm{KH}_{2} \mathrm{PO}_{4} 0,1 \mathrm{M} ; \mathrm{pH} 7,5\right), \mathrm{KNO}_{3}(0,1 \mathrm{M})$, n-propanol $(3 \% \mathrm{v} / \mathrm{v})$ e $\mathrm{NADH}$ ( $\beta$-nicotinamida adenina dinucleotídeo, forma reduzida). O n-propanol foi usado para aumentar a permeabilidade celular ao nitrato e ao nitrito. O NADH foi utilizado como doador de elétrons para ativação da enzima nitrato redutase. Isto foi necessário porque o congelamento das amostras em nitrogênio líquido inativou $\mathrm{o}$ NADH presente naturalmente na planta. O tecido vegetal, submerso na solução de incubação, foi infiltrado à vácuo durante um minuto com descanso de 30 segundos. Este procedimento foi repetido três vezes e teve por finalidade aumentar a penetração da solução nos tecidos.

Após a infiltração, os tubos foram cobertos com papel alumínio e mantidos, na ausência de luz, em banho-maria a $30{ }^{\circ} \mathrm{C}$, por 30 minutos. Finalizada a incubação efetuou-se a filtragem do material. $\mathrm{O}$ material filtrado foi diluído oito vezes em tampão fosfato. Desta diluição retirou-se uma alíquota de $1 \mathrm{~mL}$ a qual foi adicionado $1 \mathrm{~mL}$ de sulfanilamida $1 \%$ (para interromper a reação) e $1 \mathrm{~mL}$ de $\mathrm{N}$-naftiletilenodiamino $0,02 \%$. Após a adição destes reagentes procedeu-se a leitura de absorbância em espectrofotômetro a $540 \mathrm{~nm}$. A atividade da enzima foi expressa em $\mu$ moles de $\mathrm{NO}_{2}^{-}$liberados por grama de matéria fresca na solução de incubação no período de uma hora ( $\mu$ moles de $\mathrm{NO}_{2}{ }^{-} \mathrm{h}^{-1} \mathrm{~g}^{-1} \mathrm{mf}$ $\left.{ }^{1}\right)$ com base na curva padrão de $\mathrm{NaNO}_{3}(0,5,10$, $20,25,40$ e $50 \mu \mathrm{M})$ de acordo com a metodologia proposta por Jaworski (1971).

Determinou-se a produção de matéria seca da parte aérea (MSPA) e o número de perfilhos do arroz, aos 60 DAE. Para a determinação da MSPA coletouse uma planta por vaso, a qual foi secada em estufa com circulação forçada de ar e temperatura de 60$70^{\circ} \mathrm{C}$, até atingir massa constante. $\mathrm{O}$ perfilhamento foi determinado por contagem, na mesma planta em que foi determinado a MSPA.

$\mathrm{O}$ número de panículas por planta foi obtido contando-se as panículas de duas plantas por vaso, sendo o valor apresentado correspondente a média das duas plantas. O número total de espiguetas por panícula foi obtido contando-se todas as espiguetas de duas plantas por vaso e o valor apresentado corresponde a média das duas plantas. A fertilidade das espiguetas foi determinada pela relação do número de espiguetas granadas por panícula pelo número total de espiguetas por panícula $\mathrm{x} 100$. O peso de 100 grãos foi obtida pesando-se quatro amostras de 100 grãos por unidade experimental. O teor de água dos grãos foi determinado e ajustado para $13 \%$. A produtividade de grãos foi obtida pela 
colheita das panículas de duas plantas por vaso. A trilha das panículas foi realizada manualmente. $\mathrm{O}$ material passou pelo processo de limpeza para a separação das espiguetas chochas, juntamente com a palha, das epiguetas granadas. Após esta operação, os grãos foram pesados e em seguida calculou-se a produtividade em gramas por planta (teor de água de13\%).

Os dados foram submetidos à analise de variância e as médias comparadas pelo teste LSD $(\mathrm{p} \leq 0,05)$.

\section{Resultados e Discussão}

O teor de amônio no solo foi influenciado pela acidez do solo (Tabela 2). Considerando os valores médios, a partir da segunda coleta (14 DAE) constatou-se ocorrência dos maiores valores quando a acidez do solo estava alta. Entretanto, na primeira coleta os valores foram inversos provavelmente porque ainda não tivesse havido tempo para que a acidez do solo afetasse o processo de nitrificação do solo. Hayatsu e Kosuge (1993) e Crusciol et al (2011) também constataram que a elevação do $\mathrm{pH}$ proporcionou maiores taxas de nitrificação o que culmina em menores teores de amônio. Ao observar o desdobramento dos micronutrientes em cada nível de acidez, não foi constatado um tratamento que influenciou de forma semelhante o teor de amônio durante as coletas (Tabela 2). O que pode ser indicativo de que os teores de micronutrientes aplicados tiveram pouca influência no processo de nitrificação do solo. Os teores médios de amônio nas quatro épocas foram $21,8,16,8,30,6$ e 13,2 $\mathrm{mg} \mathrm{kg}^{-1}$, aos 7, 14, 21 e 28 DAE, respectivamente. Os maiores teores nas coletas aos 7 e 21 DAE ocorreram devido a época de aplicação do N. A primeira aplicação de $\mathrm{N}$ foi logo após a emergência do arroz e a outra parte aos 15 dias após a primeira, fato que favoreceu as observações em tais coletas.

Tabela 2. Teor de amônio do solo aos 7, 14, 21 e 28 dias após a emergência (DAE) em função dos níveis de acidez e da aplicação de micronutrientes. Botucatu-SP, 2009.

\begin{tabular}{|c|c|c|c|c|c|c|}
\hline \multirow{2}{*}{$\begin{array}{l}\text { Níveis } \\
\text { de acidez }\end{array}$} & \multicolumn{5}{|c|}{ Micronutriente } & \multirow{2}{*}{ Média } \\
\hline & Controle & $\mathrm{Zn}$ & $\mathrm{Fe}$ & $\mathrm{Mn}$ & $\mathrm{CQT}^{1}$ & \\
\hline & \multicolumn{6}{|c|}{$\begin{array}{l}\mathrm{NH}_{4}^{+}-\mathrm{mg} \mathrm{kg}^{-1}-{ }^{-}-\mathrm{DAE}^{-} \\
\quad 7 \mathrm{-}\end{array}$} \\
\hline Alta & 7,0abD & $21,5 \mathrm{abB}$ & $29,3 \mathrm{abA}$ & $26,2 \mathrm{bA}$ & $14,4 \mathrm{cC}$ & $19,7 \mathrm{c}$ \\
\hline Média & $5,5 \mathrm{bC}$ & $18,6 \mathrm{bB}$ & $32,3 \mathrm{aA}$ & $29,8 \mathrm{aA}$ & $20,8 \mathrm{bB}$ & $21,4 b$ \\
\hline \multirow[t]{2}{*}{ Baixa } & $10,0 \mathrm{aC}$ & $24,5 \mathrm{aB}$ & $26,2 \mathrm{bB}$ & $24,5 \mathrm{bB}$ & $36,7 \mathrm{aA}$ & $24,4 \mathrm{a}$ \\
\hline & \multicolumn{6}{|c|}{14 DAE } \\
\hline Alta & $15,0 \mathrm{bB}$ & $19,4 \mathrm{aA}$ & $20,2 \mathrm{aA}$ & $15,2 \mathrm{aB}$ & $22,6 \mathrm{aA}$ & $18,5 \mathrm{a}$ \\
\hline Média & $21,8 \mathrm{aA}$ & $16,9 \mathrm{aB}$ & $15,7 \mathrm{bB}$ & $14,6 \mathrm{aB}$ & $21,3 \mathrm{aA}$ & $18,0 \mathrm{a}$ \\
\hline \multirow[t]{2}{*}{ Baixa } & $12,5 \mathrm{bA}$ & $12,7 \mathrm{bA}$ & $14,0 \mathrm{bA}$ & $14,3 \mathrm{aA}$ & $15,5 \mathrm{bA}$ & $13,8 b$ \\
\hline & \multicolumn{6}{|c|}{$21 \mathrm{DAE}$} \\
\hline Alta & $32,5 \mathrm{aB}$ & $30,8 \mathrm{aB}$ & $32,6 \mathrm{aB}$ & $37,9 \mathrm{aA}$ & $31,2 \mathrm{aB}$ & $33,0 \mathrm{a}$ \\
\hline Média & $33,2 \mathrm{aA}$ & $27,2 \mathrm{aB}$ & $24,6 \mathrm{bB}$ & $28,5 \mathrm{bB}$ & $33,7 \mathrm{aA}$ & $29,4 b$ \\
\hline \multirow[t]{2}{*}{ Baixa } & $26,7 \mathrm{bB}$ & $31,2 \mathrm{aA}$ & $30,0 \mathrm{aAB}$ & $27,0 \mathrm{bB}$ & $32,4 \mathrm{aA}$ & $29,4 b$ \\
\hline & \multicolumn{6}{|c|}{$28 \mathrm{DAE}$} \\
\hline Alta & $14,1 \mathrm{aC}$ & $18,2 \mathrm{aB}$ & $15,1 \mathrm{aC}$ & $24,3 \mathrm{aA}$ & $16,4 \mathrm{aBC}$ & $17,6 a$ \\
\hline Média & $12,9 \mathrm{aA}$ & $6,0 \mathrm{bC}$ & $10,5 \mathrm{bAB}$ & $8,4 \mathrm{cBC}$ & $10,8 \mathrm{bAB}$ & $9,7 \mathrm{c}$ \\
\hline Baixa & $7,5 \mathrm{bC}$ & $8,1 \mathrm{bC}$ & $12,2 \mathrm{abB}$ & $16,0 \mathrm{bA}$ & $16,9 \mathrm{aA}$ & $12,1 b$ \\
\hline Média & 16,6 & 19,6 & 22,0 & 22,0 & 22,7 & - \\
\hline
\end{tabular}

${ }^{1} \mathrm{CQT}: \mathrm{Zn}+\mathrm{Fe}+\mathrm{Mn}$. Médias com a mesma letra, minúsculas nas colunas e maiúsculas nas linhas não diferem pelo teste LSD $(\mathrm{p} \leq 0,05)$.

Fonte: Elaboração dos autores. 
Os teores de $\mathrm{N}^{-} \mathrm{NO}_{3}{ }^{-}$no solo foram influenciados pela acidez do solo em todas as coletas (Tabela 3 ). Os maiores valores foram observados quando acidez foi baixa. De acordo com Fageria (2000) e Crusciol et al. (2011) o aumento do $\mathrm{pH}$ incrementa o processo de nitrificação. Entretanto, na média não se observou um efeito dos micronutrientes nos teores de nitrato no solo. Novamente, verificase o mesmo efeito que ocorreu nos teores de amônio, esses resultados podem ter ocorrido por que os teores de micronutrientes no solo estavam adequados e o suprimento deles via adubação não alterou o processo de nitrificação.

Tabela 3. Teor de nitrato do solo aos 7, 14, 21 e 28 dias após a emergência (DAE) em função dos níveis de acidez e da aplicação de micronutrientes. Botucatu-SP, 2009.

\begin{tabular}{|c|c|c|c|c|c|c|}
\hline \multirow{2}{*}{$\begin{array}{l}\text { Níveis } \\
\text { de acidez }\end{array}$} & \multicolumn{5}{|c|}{ Micronutriente } & \multirow{2}{*}{ Média } \\
\hline & Controle & $\mathrm{Zn}$ & $\mathrm{Fe}$ & $\mathrm{Mn}$ & $\mathrm{CQT}^{1}$ & \\
\hline & \multicolumn{6}{|c|}{$\begin{array}{c}7 \mathrm{DAE} \\
7 \mathrm{DE}\end{array}$} \\
\hline Alta & $24,5 \mathrm{abC}$ & $33,8 \mathrm{abA}$ & $32,9 \mathrm{bA}$ & $29,9 \mathrm{cAB}$ & $28,4 \mathrm{bBC}$ & $29,9 b$ \\
\hline Média & $20,6 \mathrm{bC}$ & $32,3 \mathrm{bB}$ & $32,3 \mathrm{bB}$ & $38,3 \mathrm{bA}$ & $33,8 \mathrm{aB}$ & $31,5 b$ \\
\hline \multirow[t]{2}{*}{ Baixa } & $25,0 \mathrm{aC}$ & $37,0 \mathrm{aB}$ & $39,4 \mathrm{aB}$ & $45,2 \mathrm{aA}$ & $37,5 \mathrm{aB}$ & $36,8 \mathrm{a}$ \\
\hline & \multicolumn{6}{|c|}{$14 \mathrm{DAE}$} \\
\hline Alta & $16,4 \mathrm{bC}$ & $26,2 \mathrm{bB}$ & $31,0 \mathrm{bA}$ & $17,9 \mathrm{cC}$ & $22,4 \mathrm{bB}$ & $22,8 \mathrm{c}$ \\
\hline Média & $30,4 \mathrm{aA}$ & $22,0 \mathrm{bB}$ & $23,8 \mathrm{cB}$ & $23,2 \mathrm{bB}$ & $30,0 \mathrm{aA}$ & $26,0 \mathrm{~b}$ \\
\hline \multirow[t]{2}{*}{ Baixa } & $33,4 \mathrm{aB}$ & $35,4 \mathrm{aAB}$ & $38,7 \mathrm{aA}$ & $33,7 \mathrm{aB}$ & $32,4 \mathrm{aB}$ & $34,7 \mathrm{a}$ \\
\hline & \multicolumn{6}{|c|}{$21 \mathrm{DAE}$} \\
\hline Alta & $41,2 \mathrm{aA}$ & $37,2 \mathrm{aAB}$ & $39,1 \mathrm{aAB}$ & $40,1 \mathrm{aAB}$ & $36,7 \mathrm{bB}$ & $38,9 b$ \\
\hline Média & $35,2 \mathrm{bC}$ & $37,1 \mathrm{aBC}$ & $41,6 \mathrm{aA}$ & $39,6 \mathrm{aAB}$ & $39,4 \mathrm{bAB}$ & $38,6 \mathrm{~b}$ \\
\hline \multirow[t]{2}{*}{ Baixa } & $42,7 \mathrm{aAB}$ & $40,6 \mathrm{aAB}$ & $42,9 \mathrm{aAB}$ & $40,2 \mathrm{aB}$ & $45,3 \mathrm{aA}$ & $42,3 a$ \\
\hline & \multicolumn{6}{|c|}{$28 \mathrm{DAE}$} \\
\hline Alta & $27,1 \mathrm{bB}$ & $31,9 \mathrm{aA}$ & $27,5 \mathrm{bAB}$ & $30,6 \mathrm{bAB}$ & $31,3 \mathrm{bAB}$ & $29,7 b$ \\
\hline Média & $28,4 \mathrm{bAB}$ & $26,5 \mathrm{bAB}$ & $31,0 \mathrm{bA}$ & $25,6 \mathrm{cB}$ & $28,5 \mathrm{bAB}$ & $28,0 \mathrm{~b}$ \\
\hline Baixa & $34,9 \mathrm{aB}$ & $28,5 \mathrm{abC}$ & $45,5 \mathrm{aA}$ & $45,0 \mathrm{aA}$ & $43,4 \mathrm{aA}$ & $39,5 \mathrm{a}$ \\
\hline Média & 30,0 & 32,4 & 35,5 & 34,0 & 34,0 & - \\
\hline
\end{tabular}

${ }^{1} \mathrm{CQT}: \mathrm{Zn}+\mathrm{Fe}+\mathrm{Mn}$. Médias com a mesma letra, minúsculas nas colunas e maiúsculas nas linhas não diferem pelo teste LSD $(\mathrm{p} \leq 0,05)$.

Fonte: Elaboração dos autores.

O teor de cobre $(\mathrm{Cu})$ no arroz foi influenciado pela acidez do solo (Tabela 4). De maneira geral, constatou-se ocorrência dos maiores teores quando a acidez foi média ( $\mathrm{pH}$ 5,5), com exceção da coleta aos 28 DAE. Assim os teores de $\mathrm{Cu}$ nas plantas de arroz variaram de 8,5 a $30,3 \mathrm{mg} \mathrm{kg}^{-1} \mathrm{e}$ estavam dentro a faixa ideal da cultura que é de 3-25 mg kg-1 (RAIJ et al., 1996). Observando-se o desdobramento dos micronutrientes em cada nível de acidez, não constatou-se um tratamento que influenciasse de forma semelhante o teor de $\mathrm{Cu}$ durante as coletas (Tabela 4). Entretanto na última avaliação (28DAE), verificou-se maiores teores de $\mathrm{Cu}$ em condições de alta acidez, o que pode ser reflexo da maior disponibilidade desse nutriente em menores pH. Segundo Malavolta (1980) quando o $\mathrm{pH}$ sobe forma-se hidróxidos e carbonatos menos disponíveis, consequentemente cai a concentração desse elemento na solução do solo. Os menores teores de $\mathrm{Cu}$ foram observados na coleta aos $28 \mathrm{DAE}$. Estes valores demonstram que ocorreu a diluição do micronutriente. Com o tempo de coleta ocorreu 
aumento na produção de matéria seca e diminuição da concentração do elemento na planta. Este efeito ocorre quando a taxa de crescimento relativo de matéria seca é superior à taxa de absorção relativa do nutriente (MALAVOLTA, 1980).

Os teores de zinco ( $\mathrm{Zn}$ ) na parte aérea do arroz foram influenciados pela acidez do solo. Os maiores valores médios foram observados quando a acidez do solo foi alta ( $\mathrm{pH} 4,5)$. De acordo com Tisdale, Nelson e Beaton (1985) a disponibilidade de $\mathrm{Zn}$ no solo diminui cerca de 100 vezes com o aumento de uma unidade de pH. Com a redução da disponibilidade dos micronutrientes no solo é de se esperar que também haverá diminuição na planta, o que de fato ocorreu. Em trabalhos com soja também foi observado a redução na concentração foliar de $\mathrm{Zn}$, em razão do aumento do $\mathrm{pH}$ do solo (CAIRES et al., 2001). Com o desdobramento dos dados em cada nível de acidez observou-se que em todas as coletas a aplicação de $\mathrm{Zn}$ no solo proporcionou as maiores concentrações de $\mathrm{Zn}$ na parte aérea. Esse resultado foi observado quando se aplicou somente o Zn ou quando o elemento foi aplicado juntamente com Fe e Mn (Tabela 5). Também Moreira et al. (2003) relataram que o aumento da disponibilidade de Mn na solução induziu a maior absorção de Zn pelas raízes de arroz. Entretanto, no presente estudo a aplicação somente do $\mathrm{Mn}$ não proporcionou aumento das concentrações de $\mathrm{Zn}$ na planta. O que pode ser indicativo de que a planta estava bem nutrida com esse elemento, como observado nos teores de $\mathrm{Zn}$ e comparado com a faixa ideal da cultura (MALAVOLTA, 1980).

Tabela 4. Teor de cobre na parte aérea do arroz aos 7, 14, 21 e 28 dias após a emergência (DAE) em função dos níveis de acidez do solo e da aplicação de micronutrientes. Botucatu-SP, 2009.

\begin{tabular}{|c|c|c|c|c|c|c|}
\hline \multirow{3}{*}{$\begin{array}{c}\text { Níveis } \\
\text { de acidez }\end{array}$} & \multicolumn{5}{|c|}{ Micronutriente } & \multirow{2}{*}{ Média } \\
\hline & Controle & $\mathrm{Zn}$ & $\mathrm{Fe}$ & $\mathrm{Mn}$ & $\mathrm{CQT}^{1}$ & \\
\hline & \multicolumn{6}{|c|}{$7 \mathrm{DAE}$} \\
\hline Alta & $29,0 \mathrm{bA}$ & $30,0 \mathrm{aA}$ & $26,3 \mathrm{bA}$ & $31,3 \mathrm{bA}$ & $32,0 \mathrm{aA}$ & $29,7 b$ \\
\hline Média & $40,0 \mathrm{aA}$ & $25,0 \mathrm{aC}$ & $35,3 \mathrm{aAB}$ & $38,7 \mathrm{aA}$ & $31,0 \mathrm{aBC}$ & $34,0 \mathrm{a}$ \\
\hline \multirow[t]{2}{*}{ Baixa } & $32,7 \mathrm{bA}$ & $27,0 \mathrm{aA}$ & $31,0 \mathrm{abA}$ & $32,3 \mathrm{bA}$ & $28,3 \mathrm{aA}$ & $30,3 b$ \\
\hline & \multicolumn{6}{|c|}{$14 \mathrm{DAE}$} \\
\hline Alta & $26,3 \mathrm{aA}$ & $24,0 \mathrm{aAB}$ & $22,3 \mathrm{bB}$ & $23,6 \mathrm{abAB}$ & $22,3 \mathrm{aB}$ & $23,7 b$ \\
\hline Média & $28,0 \mathrm{aA}$ & $24,3 \mathrm{aAB}$ & $22,4 \mathrm{aB}$ & $23,0 \mathrm{bB}$ & $25,0 \mathrm{aAB}$ & $24,5 \mathrm{ab}$ \\
\hline \multirow[t]{2}{*}{ Baixa } & $27,7 \mathrm{aA}$ & $23,3 \mathrm{aB}$ & $25,7 \mathrm{bAB}$ & $27,3 \mathrm{aA}$ & $25,7 \mathrm{aAB}$ & $26,0 \mathrm{a}$ \\
\hline & \multicolumn{6}{|c|}{$21 \mathrm{DAE}$} \\
\hline Alta & $12,0 \mathrm{bB}$ & $12,0 \mathrm{bB}$ & $12,0 \mathrm{bB}$ & $18,0 \mathrm{bA}$ & $15,3 \mathrm{abA}$ & $13,8 \mathrm{c}$ \\
\hline Média & $17,7 \mathrm{aB}$ & $17,0 \mathrm{abBC}$ & $16,4 \mathrm{aBC}$ & $24,0 \mathrm{aA}$ & $14,3 \mathrm{bC}$ & $17,8 \mathrm{a}$ \\
\hline \multirow{2}{*}{ Baixa } & $17,7 \mathrm{aA}$ & $14,7 \mathrm{aA}$ & $15,0 \mathrm{abA}$ & $16,4 \mathrm{bA}$ & $17,7 \mathrm{aA}$ & $16,3 b$ \\
\hline & \multicolumn{6}{|c|}{$28 \mathrm{DAE}$} \\
\hline Alta & $13,4 \mathrm{aAB}$ & $14,2 \mathrm{aA}$ & $11,2 \mathrm{aB}$ & $12,0 \mathrm{aB}$ & $12,7 \mathrm{aAB}$ & $12,7 \mathrm{a}$ \\
\hline Média & $6,0 \mathrm{bB}$ & $8,0 \mathrm{bAB}$ & $10,0 \mathrm{aA}$ & $9,3 \mathrm{bA}$ & $9,4 \mathrm{bA}$ & $8,5 \mathrm{~b}$ \\
\hline Baixa & $6,0 \mathrm{bB}$ & $8,0 \mathrm{bAB}$ & $11,2 \mathrm{aA}$ & $9,0 \mathrm{bB}$ & $12,3 \mathrm{aA}$ & $9,3 \mathrm{~b}$ \\
\hline Média & 21,4 & 19,0 & 20,0 & 22,0 & 20,5 & - \\
\hline
\end{tabular}

${ }^{1} \mathrm{CQT}: \mathrm{Zn}+\mathrm{Fe}+\mathrm{Mn}$. Médias com a mesma letra, minúsculas nas colunas e maiúsculas nas linhas não diferem pelo teste LSD $(\mathrm{p} \leq 0,05)$.

Fonte: Elaboração dos autores. 
Tabela 5. Teor de zinco na parte aérea do arroz aos 7, 14, 21 e 28 dias após a emergência (DAE) em função dos níveis de acidez do solo e da aplicação de micronutrientes. Botucatu-SP, 2009.

\begin{tabular}{|c|c|c|c|c|c|c|}
\hline \multirow{2}{*}{$\begin{array}{c}\text { Níveis } \\
\text { de acidez }\end{array}$} & \multicolumn{5}{|c|}{ Micronutriente } & \multirow{2}{*}{ Média } \\
\hline & Controle & $\mathrm{Zn}$ & $\mathrm{Fe}$ & $\mathrm{Mn}$ & $\mathrm{CQT}^{1}$ & \\
\hline & \multicolumn{6}{|c|}{ - } \\
\hline Alta & $44,0 \mathrm{aD}$ & $72,0 \mathrm{aB}$ & $54,7 \mathrm{aC}$ & $70,3 \mathrm{aB}$ & $80,0 \mathrm{aA}$ & $64,2 \mathrm{a}$ \\
\hline Média & $39,0 \mathrm{bC}$ & $55,0 \mathrm{bA}$ & $39,0 \mathrm{bC}$ & $48,2 \mathrm{bB}$ & $55,0 \mathrm{bA}$ & $47,2 b$ \\
\hline \multirow[t]{2}{*}{ Baixa } & $33,7 \mathrm{cB}$ & $44,0 \mathrm{cA}$ & $31,7 \mathrm{cB}$ & $32,7 \mathrm{cB}$ & $40,0 \mathrm{cA}$ & $36,4 \mathrm{c}$ \\
\hline & \multicolumn{6}{|c|}{$14 \mathrm{DAE}$} \\
\hline Alta & $41,7 \mathrm{aB}$ & $57,0 \mathrm{aA}$ & $46,0 \mathrm{aB}$ & $45,0 \mathrm{aB}$ & $63,0 \mathrm{aA}$ & $50,5 \mathrm{a}$ \\
\hline Média & $32,0 \mathrm{bBC}$ & $58,0 \mathrm{aA}$ & $30,0 \mathrm{bC}$ & $32,0 \mathrm{bBC}$ & $39,0 \mathrm{bB}$ & $38,2 b$ \\
\hline \multirow[t]{2}{*}{ Baixa } & $13,7 \mathrm{cB}$ & $44,0 \mathrm{bA}$ & $15,7 \mathrm{cB}$ & $16,7 \mathrm{cB}$ & $40,0 \mathrm{bA}$ & $26,0 \mathrm{c}$ \\
\hline & \multicolumn{6}{|c|}{$21 \mathrm{DAE}$} \\
\hline Alta & $58,6 \mathrm{aC}$ & $76,6 \mathrm{bB}$ & $61,7 \mathrm{aC}$ & $60,8 \mathrm{aC}$ & $85,0 \mathrm{aA}$ & $68,5 \mathrm{a}$ \\
\hline Média & $47,6 \mathrm{bD}$ & $84,0 \mathrm{aA}$ & $59,0 \mathrm{aC}$ & $43,0 \mathrm{bD}$ & $74,0 \mathrm{bB}$ & $61,5 b$ \\
\hline \multirow[t]{2}{*}{ Baixa } & $30,7 \mathrm{cD}$ & $79,6 \mathrm{abA}$ & $38,8 \mathrm{bC}$ & $33,5 \mathrm{cCD}$ & $51,0 \mathrm{cB}$ & $46,7 \mathrm{c}$ \\
\hline & \multicolumn{6}{|c|}{$28 \mathrm{DAE}$} \\
\hline Alta & $53,0 \mathrm{aC}$ & $68,0 \mathrm{aB}$ & $55,0 \mathrm{aC}$ & $60,0 \mathrm{aBC}$ & $80,7 \mathrm{aA}$ & $63,3 a$ \\
\hline Média & $42,6 \mathrm{bBC}$ & $64,0 \mathrm{aA}$ & $47,0 \mathrm{bB}$ & $38,0 \mathrm{bC}$ & $66,0 \mathrm{bA}$ & $51,5 b$ \\
\hline Baixa & $33,0 \mathrm{cB}$ & $54,0 \mathrm{bA}$ & $35,0 \mathrm{cB}$ & $40,7 \mathrm{bB}$ & $53,6 \mathrm{cA}$ & $43,3 c$ \\
\hline Média & 39,0 & 63,0 & 42,8 & 43,4 & 60,6 & - \\
\hline
\end{tabular}

${ }^{1} \mathrm{CQT}: \mathrm{Zn}+\mathrm{Fe}+\mathrm{Mn}$. Médias com a mesma letra, minúsculas nas colunas e maiúsculas nas linhas não diferem pelo teste LSD $(\mathrm{p} \leq 0,05)$.

Fonte: Elaboração dos autores.

Os teores de ferro (Fe) no solo foram influenciados pelos níveis de acidez (Tabela 6), sendo que, os valores na planta não diminuíram com o aumento do $\mathrm{pH}$ do solo. De acordo com Tisdale, Nelson e Beaton (1985) a disponibilidade de Fe diminui cerca de 1.000 vezes com o aumento de uma unidade de $\mathrm{pH}$. O fato que pode explicar a pouca influência do $\mathrm{pH}$ nos teores de Fe na planta é que latossolos são ricos em $\mathrm{Fe}$, tanto que Korndörfer et al. (1999) relatam que o teor de óxido de ferro em Latossolo Vermelho distroférrico é alto e pode até causar toxidez a planta de arroz.

Os teores de manganês (Mn) na parte aérea do arroz foram influenciados pela acidez do solo em todas as coletas (Tabela 7). De modo geral, os maiores valores foram observados quando a acidez do solo foi alta $(\mathrm{pH} 4,5)$ e os menores quando a acidez do solo foi baixa ( $\mathrm{pH}$ 6,3). Tisdale, Nelson e Beaton (1985) relataram que o aumento de uma unidade no valor do $\mathrm{pH}$ diminuiu em cerca de 100 vezes a disponibilidade de Mn no solo. Estes dados justificam a redução de manganês na parte aérea do arroz com o aumento do pH. Também Caires e Fonseca (2000) observaram redução dos teores de Mn na cultura da soja em decorrência do aumento do $\mathrm{pH}$ do solo. Com o desdobramento dos dados em cada nível de acidez observou-se que de maneira geral a aplicação de $\mathrm{Mn}$ no solo proporcionou os maiores teores do elemento na parte aérea do arroz. Esse resultado é facilmente constatado quando se observa a média das quatro coletas (Tabela 7). 
Tabela 6. Teor de ferro na parte aérea do arroz aos 7, 14, 21 e 28 dias após a emergência (DAE) em função dos níveis de acidez do solo e da aplicação de micronutrientes. Botucatu-SP, 2009.

\begin{tabular}{|c|c|c|c|c|c|c|}
\hline \multirow{2}{*}{$\begin{array}{c}\text { Níveis } \\
\text { de acidez }\end{array}$} & \multicolumn{5}{|c|}{ Micronutriente } & \multirow{2}{*}{ Média } \\
\hline & Controle & $\mathrm{Zn}$ & $\mathrm{Fe}$ & $\mathrm{Mn}$ & $\mathrm{CQT}^{1}$ & \\
\hline & \multicolumn{6}{|c|}{7 DAE } \\
\hline Alta & $177,0 \mathrm{cC}$ & $251,0 \mathrm{aA}$ & $230,0 \mathrm{aB}$ & $231,0 \mathrm{aB}$ & $161,0 \mathrm{bC}$ & $210,0 \mathrm{a}$ \\
\hline Média & $231,0 \mathrm{bA}$ & $155,0 \mathrm{bC}$ & $186,0 \mathrm{bB}$ & $151,0 \mathrm{bC}$ & $146,0 \mathrm{bC}$ & $174,0 \mathrm{c}$ \\
\hline \multirow[t]{2}{*}{ Baixa } & $274,0 \mathrm{aA}$ & $165,0 \mathrm{bC}$ & $197,0 \mathrm{bB}$ & $145,0 \mathrm{bD}$ & $196,0 \mathrm{aB}$ & $195,4 b$ \\
\hline & \multicolumn{6}{|c|}{$14 \mathrm{DAE}$} \\
\hline Alta & $228,0 \mathrm{aA}$ & $188,0 \mathrm{bC}$ & $196,0 \mathrm{bBC}$ & $187,0 \mathrm{bC}$ & $211,0 \mathrm{bB}$ & $202,0 \mathrm{c}$ \\
\hline Média & $205,0 \mathrm{bB}$ & $182,0 \mathrm{bC}$ & $252,0 \mathrm{aA}$ & $247,0 \mathrm{aA}$ & $247,0 \mathrm{aA}$ & $226,0 \mathrm{~b}$ \\
\hline \multirow[t]{2}{*}{ Baixa } & $242,0 \mathrm{aAB}$ & $254,0 \mathrm{aA}$ & $240,0 \mathrm{aAB}$ & $235,0 \mathrm{aB}$ & $248,0 \mathrm{aAB}$ & $244,0 \mathrm{a}$ \\
\hline & \multicolumn{6}{|c|}{$21 \mathrm{DAE}$} \\
\hline Alta & $246,0 \mathrm{aA}$ & $173,0 \mathrm{bB}$ & $258,0 \mathrm{aA}$ & $236,0 \mathrm{aA}$ & $231,0 \mathrm{aA}$ & $243,0 \mathrm{a}$ \\
\hline Média & $247,0 \mathrm{aA}$ & $172,0 \mathrm{bB}$ & $256,0 \mathrm{aA}$ & $251,0 \mathrm{aA}$ & $249,0 \mathrm{aA}$ & $235,0 \mathrm{a}$ \\
\hline \multirow[t]{2}{*}{ Baixa } & $221,0 \mathrm{aB}$ & $257,0 \mathrm{aA}$ & $230,0 \mathrm{aAB}$ & $236,0 \mathrm{aAB}$ & $248,0 \mathrm{aAB}$ & $238,0 \mathrm{a}$ \\
\hline & \multicolumn{6}{|c|}{$28 \mathrm{DAE}$} \\
\hline Alta & $57,0 \mathrm{bD}$ & $96,0 \mathrm{bA}$ & $76,0 \mathrm{abC}$ & $76,0 \mathrm{bC}$ & $85,0 \mathrm{bB}$ & $78,0 \mathrm{~b}$ \\
\hline Média & $85,0 \mathrm{aB}$ & $75,0 \mathrm{cC}$ & $73,0 \mathrm{bC}$ & $74,0 \mathrm{bC}$ & $93,0 \mathrm{aA}$ & $80,0 \mathrm{~b}$ \\
\hline Baixa & $56,0 \mathrm{bC}$ & $115,0 \mathrm{aA}$ & $82,0 \mathrm{aB}$ & $86,0 \mathrm{aB}$ & $82,0 \mathrm{bB}$ & $84,0 \mathrm{a}$ \\
\hline Média & 189,0 & 174,0 & 190,0 & 180,0 & 183,0 & - \\
\hline
\end{tabular}

${ }^{1} \mathrm{CQT}: \mathrm{Zn}+\mathrm{Fe}+\mathrm{Mn}$. Médias com a mesma letra, minúsculas nas colunas e maiúsculas nas linhas não diferem pelo teste LSD $(\mathrm{p} \leq 0,05)$.

Fonte: Elaboração dos autores.

Tabela 7. Teor de manganês na parte aérea do arroz aos 7, 14, 21 e 28 dias após a emergência (DAE) em função dos níveis de acidez do solo e da aplicação de micronutrientes. Botucatu-SP, 2009.

\begin{tabular}{|c|c|c|c|c|c|c|}
\hline \multirow{2}{*}{$\begin{array}{c}\text { Níveis } \\
\text { de acidez }\end{array}$} & \multicolumn{5}{|c|}{ Micronutriente } & \multirow{2}{*}{ Média } \\
\hline & Controle & $\mathrm{Zn}$ & $\mathrm{Fe}$ & $\mathrm{Mn}$ & $\mathrm{CQT}^{1}$ & \\
\hline & \multicolumn{6}{|c|}{ 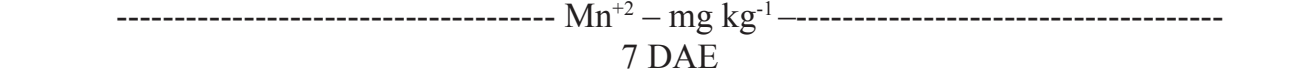 } \\
\hline Alta & $672 \mathrm{aAB}$ & $608 \mathrm{aC}$ & $597 \mathrm{aC}$ & $658 \mathrm{aB}$ & $685 \mathrm{aA}$ & $644 a$ \\
\hline Média & $113 \mathrm{bC}$ & $105 \mathrm{bC}$ & 199bA & 176bB & $189 \mathrm{bAB}$ & $156 b$ \\
\hline \multirow[t]{2}{*}{ Baixa } & $128 \mathrm{bB}$ & $93 \mathrm{bC}$ & $163 \mathrm{cA}$ & $175 b A$ & $126 \mathrm{cB}$ & $137 \mathrm{c}$ \\
\hline & \multicolumn{6}{|c|}{$14 \mathrm{DAE}$} \\
\hline Alta & $528 \mathrm{aB}$ & $513 \mathrm{aBC}$ & $499 \mathrm{aC}$ & $525 \mathrm{aB}$ & $546 a A$ & $522 \mathrm{a}$ \\
\hline Média & 204bB & $243 \mathrm{bA}$ & $248 \mathrm{bA}$ & $242 \mathrm{bA}$ & $200 \mathrm{bB}$ & $227 b$ \\
\hline \multirow[t]{2}{*}{ Baixa } & $138 \mathrm{cC}$ & $168 \mathrm{cB}$ & $187 \mathrm{cA}$ & $202 \mathrm{cA}$ & $144 \mathrm{cC}$ & $168 \mathrm{c}$ \\
\hline & \multicolumn{6}{|c|}{$21 \mathrm{DAE}$} \\
\hline Alta & $864 \mathrm{aB}$ & $886 \mathrm{aB}$ & $952 \mathrm{aA}$ & $947 \mathrm{aA}$ & $933 \mathrm{aA}$ & $916 a$ \\
\hline Média & $442 b D$ & $480 \mathrm{bC}$ & $486 \mathrm{bC}$ & $582 \mathrm{bA}$ & $527 \mathrm{bB}$ & $503 b$ \\
\hline \multirow{2}{*}{ Baixa } & $440 \mathrm{bB}$ & $457 \mathrm{bB}$ & $492 \mathrm{bA}$ & $472 \mathrm{cAB}$ & $440 \mathrm{cB}$ & $460 \mathrm{c}$ \\
\hline & \multicolumn{6}{|c|}{$28 \mathrm{DAE}$} \\
\hline Alta & $1.065 \mathrm{aC}$ & $1.152 \mathrm{aAB}$ & $1.131 \mathrm{aB}$ & $1.188 \mathrm{aA}$ & $1.060 \mathrm{aC}$ & $1.119 \mathrm{a}$ \\
\hline Média & $484 \mathrm{bC}$ & $358 \mathrm{cD}$ & $761 \mathrm{bA}$ & $578 b B$ & $474 \mathrm{bC}$ & $531 \mathrm{~b}$ \\
\hline Baixa & $410 \mathrm{cB}$ & $425 \mathrm{bB}$ & $415 \mathrm{cB}$ & $613 \mathrm{bA}$ & $404 \mathrm{cB}$ & $453 \mathrm{c}$ \\
\hline Média & 457 & 457 & 511 & 530 & 477 & - \\
\hline
\end{tabular}

${ }^{1} \mathrm{CQT}: \mathrm{Zn}+\mathrm{Fe}+\mathrm{Mn}$. Médias com a mesma letra, minúsculas nas colunas e maiúsculas nas linhas não diferem pelo teste LSD $(\mathrm{p} \leq 0,05)$.

Fonte: Elaboração dos autores. 
A atividade da enzima nitrato redutase (NR) foi influenciada pela acidez do solo em todas as épocas de coleta (Tabela 8). De maneira geral, a maior atividade foi constatada em condições de acidez média aos 7 e 14 DAE ( $\mathrm{pH}$ 5,5). A maior atividade da NR para a acidez média pode ser atribuída a maior disponibilidade de nutrientes nesta condição e ao balanço nitrato/amônio. $\mathrm{Na}$ acidez média a proporção nitrato/amônio foi 1,5 e na baixa acidez 1,9 (Tabelas 2 e 3). Como já foi discutido anteriormente, a planta de arroz se desenvolve melhor em ambientes com quantidades semelhantes entre nitrato e amônio (TA; OHIRA, 1981; LIN et al., 2005; LI et al., 2007; POLETTO et al., 2011). Neste caso, a proporção nitrato/amônio da acidez média foi mais favorável ao bom desenvolvimento do arroz e, consequentemente, para a atividade da NR. Aos 21 e 28 DAE também houve maior atividade da NR na acidez baixa, o que pode ser reflexo dos maiores teores de nitrato nesse ambiente (Tabela 3). A maior disponibilidade de nitrato pode interferir positivamente no aumento da atividade da NR, pois trata-se do substrato da enzima (MALAVOLTA, 1980).

Tabela 8. Atividade da enzima nitrato redutase em folhas de arroz aos 7, 14, 21 e 28 dias após a emergência (DAE) em função dos níveis de acidez do solo e da aplicação de micronutrientes. Botucatu-SP, 2009.

\begin{tabular}{|c|c|c|c|c|c|c|}
\hline \multirow{2}{*}{$\begin{array}{c}\text { Níveis } \\
\text { de acidez }\end{array}$} & \multicolumn{5}{|c|}{ Micronutriente } & \multirow{2}{*}{ Média } \\
\hline & Controle & $\mathrm{Zn}$ & $\mathrm{Fe}$ & $\mathrm{Mn}$ & $\mathrm{CQT}^{1}$ & \\
\hline & \multicolumn{6}{|c|}{${ }^{2} \mathrm{NO}_{2}^{-}\left(\mu \mathrm{Mg} \text { de matéria fresca } \mathrm{h}^{-1}\right)^{2}$} \\
\hline Alta & $14,4 \mathrm{aA}$ & $13,3 \mathrm{aAB}$ & $13,6 \mathrm{aAB}$ & $13,2 \mathrm{aAB}$ & $12,7 \mathrm{bB}$ & $13,4 \mathrm{a}$ \\
\hline Média & $12,1 \mathrm{bB}$ & $13,5 \mathrm{aAB}$ & $13,3 \mathrm{aAB}$ & $13,6 \mathrm{aA}$ & $14,7 \mathrm{aA}$ & $13,4 \mathrm{a}$ \\
\hline \multirow[t]{2}{*}{ Baixa } & $11,1 \mathrm{bBC}$ & $11,7 \mathrm{bB}$ & $10,2 \mathrm{bC}$ & $12,3 \mathrm{aAB}$ & $13,6 \mathrm{abA}$ & $11,8 b$ \\
\hline & \multicolumn{6}{|c|}{$14 \mathrm{DAE}$} \\
\hline Alta & $8,5 \mathrm{bA}$ & $8,3 \mathrm{bA}$ & $8,6 \mathrm{aA}$ & $7,2 \mathrm{cA}$ & $8,1 \mathrm{bA}$ & $8,1 \mathrm{c}$ \\
\hline Média & $14,1 \mathrm{aA}$ & $11,7 \mathrm{aB}$ & $10,7 \mathrm{aB}$ & $13,8 \mathrm{aA}$ & $11,4 \mathrm{aB}$ & $12,3 \mathrm{a}$ \\
\hline \multirow[t]{2}{*}{ Baixa } & $9,9 \mathrm{bB}$ & $10,4 \mathrm{aB}$ & $9,3 \mathrm{aB}$ & $11,1 \mathrm{bAB}$ & $12,6 \mathrm{aA}$ & $10,7 b$ \\
\hline & \multicolumn{6}{|c|}{$21 \mathrm{DAE}$} \\
\hline Alta & $3,5 \mathrm{bB}$ & $4,2 \mathrm{bAB}$ & $5,3 \mathrm{bA}$ & $4,4 \mathrm{bAB}$ & $3,7 \mathrm{bB}$ & $4,2 b$ \\
\hline Média & $7,0 \mathrm{aAB}$ & 7,9aA & $6,3 \mathrm{bB}$ & $7,4 \mathrm{aAB}$ & $7,2 \mathrm{aAB}$ & $7,2 \mathrm{a}$ \\
\hline \multirow[t]{2}{*}{ Baixa } & $7,7 \mathrm{aA}$ & $7,9 \mathrm{aA}$ & $8,0 \mathrm{aA}$ & $7,6 \mathrm{aA}$ & $7,2 \mathrm{aA}$ & $7,7 \mathrm{a}$ \\
\hline & \multicolumn{6}{|c|}{$28 \mathrm{DAE}$} \\
\hline Alta & $3,1 \mathrm{cAB}$ & $2,9 \mathrm{bAB}$ & $3,4 \mathrm{bA}$ & $2,3 \mathrm{bB}$ & $2,4 \mathrm{bB}$ & $2,8 \mathrm{~b}$ \\
\hline Média & $5,4 \mathrm{bBC}$ & $4,6 \mathrm{aC}$ & $6,4 \mathrm{aA}$ & $6,2 \mathrm{aAB}$ & $5,8 \mathrm{aAB}$ & $5,7 \mathrm{a}$ \\
\hline Baixa & $6,6 \mathrm{aA}$ & $4,8 \mathrm{aC}$ & $3,9 \mathrm{bD}$ & $5,6 \mathrm{aBC}$ & $6,4 \mathrm{aAB}$ & $5,5 \mathrm{a}$ \\
\hline Média & 8,6 & 8,4 & 8,3 & 8,7 & 8,8 & - \\
\hline
\end{tabular}

${ }^{1} \mathrm{CQT}: \mathrm{Zn}+\mathrm{Fe}+\mathrm{Mn} ;{ }^{2}$ atividade da NR expressa pela quantidade de nitrito $\left(\mathrm{NO}_{2}^{-}\right)$formado. Médias com a mesma letra, minúsculas nas colunas e maiúsculas nas linhas não diferem pelo teste $\operatorname{LSD}(\mathrm{p} \leq 0,05)$.

Fonte: Elaboração dos autores.

Com o desdobramento dos micronutrientes em cada nível de acidez verificou-se que a atividade enzimática foi influenciada pela aplicação de micronutrientes (Tabela 8). Nenhum dos tratamentos se destacou, não havendo diferenças entre os tratamentos. Entretanto vale destacar que, em condições de baixa acidez ocorreu aumento da atividade da NR em presença de Mn ou do coquetel (que também tem MN). Isso pode ser explicado pois em condição de baixa disponibilidade do nutriente (baixa acidez), a aplicação via fertilizante proporcionou incremento na atividade da NR. Por 
outro lado, a adição do Fe não proporcionou efeito, uma vez que esse nutriente existe em abundancia nos Latossolos, como descrito anteriormente. O Fe e o Mn atuam no transporte de elétrons e os processos envolvidos são afetados, dentre eles a redução de nitrato. Isto acarreta acúmulo de nitrito podendo exercer um controle em feedback sobre a nitrato redutase de tal modo que o $\mathrm{NO}_{3}^{-}$se acumula, como, algumas vezes, é observado em plantas deficientes em Fe e Mn (KIRKBY; RÖMHELD, 2007). A atividade da NR diminuiu com o tempo de desenvolvimento do arroz. Mediante os resultados, constata-se que ocorreu diluição da quantidade de $\mathrm{NO}_{2}^{-}$formada. Com o tempo de coleta ocorreu aumento na produção de matéria seca e diminuição da concentração do nitrito formado na parte aérea das plantas.

A matéria seca da parte aérea (MSPA), aos 60 DAE, não diferiu entre a acidez média ( $\mathrm{pH} 5,5)$ e alta (pH 4,5), com exceção do controle (Tabela 9). No entanto, ambos proporcionaram incrementos em relação a acidez baixa (pH 6,3), com exceção ao Zn. Quanto ao desdobramento dos micronutrientes em cada nível de acidez, observou-se que para a acidez média e alta a adição de micronutrientes proporcionou incrementos de MSPA em relação ao controle. Para a acidez baixa, a adição dos micronutrientes $\mathrm{Mn}$ e $\mathrm{Fe}$ não proporcionaram acréscimos de MSPA. Plantas maiores absorvem maiores quantidades de nutrientes, ou seja tem maior efeito concentração. Nesse sentido, o arroz de terras altas tem como característica se desenvolver melhor em ambientes com acidez alta e media (MALAVOLTA, 1980; FAGERIA, 2000). Assim, em condições de baixa acidez, a planta se desenvolve menos, produziu menos MSPA e absorveu menos nutrientes, dessa forma mesmo a aplicação via foliar não proporcionou incrementos nesse parâmetro.

O número de perfilhos por planta foi influenciado pela acidez do solo de forma semelhante ao MSPA, ou seja, houve diferenças entre a acidez média e alta apenas na ausência de micronutrientes (Tabela 9). O maior número de panículas por planta foi observado com a acidez média, em relação ao efeito dos micronutrientes em cada nível de acidez constatouse maiores efeitos com a adição do Zn, sozinho ou no coquetel $(\mathrm{Mn}+\mathrm{Zn}+\mathrm{Fe})$. A cultura do arroz possui alta resposta à aplicação de Zn (FAGERIA, 2000). Plantas com deficiência de Zn, em estágios iniciais de desenvolvimento, têm seu desenvolvimento afetado e dificilmente poderão expressar seu máximo potencial genético (EPSTEIN; BLOOM, 2006).

O número de espiguetas por panícula foi pouco alterado pela variação da acidez do solo, e o efeito dos micronutrientes em cada índice de acidez foi pouco expressivo (Tabela 9). A fertilidade das espiguetas foi maior em baixa acidez, provavelmente devido ao menor número panículas por planta, resultando em menor número de espiguetas para granar e, consequentemente, menor esterilidade das espiguetas (FAGERIA, 2000). Constatouse os menores valores do peso de 100 grãos na condição de alta acidez do solo com a aplicação de Fe (Tabela 9). O que pode ser explicado pela maior disponibilidade desse nutriente (Tabela 1) nesse tipo de ambiente (mais ácido), que juntamente com a presença nos latossolos poderia causar uma certa toxidez (FAGERIA, 2000). 
Tabela 9. Matéria seca da parte aérea e número de perfilhos por planta aos $60 \mathrm{DAE}$ e componentes da produção e produtividade de grãos do arroz de terras altas em função dos níveis de acidez do solo e da aplicação de micronutrientes. Botucatu-SP, 2009.

\begin{tabular}{|c|c|c|c|c|c|c|}
\hline \multirow{2}{*}{$\begin{array}{c}\text { Níveis } \\
\text { de acidez }\end{array}$} & \multicolumn{5}{|c|}{ Micronutriente } & \multirow{2}{*}{ Média } \\
\hline & Controle & $\mathrm{Zn}$ & $\mathrm{Fe}$ & $\mathrm{Mn}$ & $\mathrm{CQT}^{1}$ & \\
\hline & \multicolumn{6}{|c|}{ Matéria seca da parte aérea $\left(\mathrm{g}\right.$ planta $\left.{ }^{-1}\right)$} \\
\hline Alta & $16 \mathrm{bB}$ & $22 \mathrm{aA}$ & $19 \mathrm{aAB}$ & $21 \mathrm{aA}$ & $21 \mathrm{aA}$ & $19,8 b$ \\
\hline Média & $20 \mathrm{aB}$ & $25 \mathrm{aA}$ & $21 \mathrm{aAB}$ & $23 \mathrm{aAB}$ & $24 \mathrm{aA}$ & $22,6 a$ \\
\hline Baixa & $13 \mathrm{bBC}$ & $13 \mathrm{bBC}$ & $19 \mathrm{aA}$ & $12 \mathrm{bC}$ & $17 \mathrm{bAB}$ & $14,8 \mathrm{c}$ \\
\hline \multirow[t]{2}{*}{ Média } & $16 \mathrm{~B}$ & $20 \mathrm{~A}$ & $20 \mathrm{~A}$ & $19 \mathrm{~A}$ & $21 \mathrm{~A}$ & - \\
\hline & \multicolumn{6}{|c|}{ Perfilhos (n. ${ }^{o}$ planta $\left.^{-1}\right)$} \\
\hline Alta & $13 \mathrm{bB}$ & $18 \mathrm{aA}$ & $19 \mathrm{aA}$ & $19 \mathrm{aA}$ & $18 \mathrm{aA}$ & $17,4 \mathrm{a}$ \\
\hline Média & $16 \mathrm{aB}$ & $20 \mathrm{aA}$ & $17 \mathrm{aB}$ & $19 \mathrm{aAB}$ & $19 \mathrm{aAB}$ & $18,2 \mathrm{a}$ \\
\hline Baixa & $12 \mathrm{bA}$ & $12 \mathrm{bA}$ & $13 \mathrm{bA}$ & $12 \mathrm{bA}$ & $13 \mathrm{bA}$ & $12,4 \mathrm{~b}$ \\
\hline \multirow{2}{*}{ Média } & 14B & $17 \mathrm{~A}$ & $16 \mathrm{~A}$ & $17 \mathrm{~A}$ & $17 \mathrm{~A}$ & - \\
\hline & \multicolumn{6}{|c|}{ Panículas (n. ${ }^{\circ}$ planta $\left.^{-1}\right)$} \\
\hline Alta & $12 \mathrm{bC}$ & $15 \mathrm{aA}$ & $11 \mathrm{bC}$ & $13 \mathrm{aB}$ & $15 \mathrm{aA}$ & $13 b$ \\
\hline Média & $14 \mathrm{aB}$ & $16 \mathrm{aA}$ & $14 \mathrm{aB}$ & $14 \mathrm{aB}$ & $14 \mathrm{aB}$ & $14 \mathrm{a}$ \\
\hline Baixa & $9 \mathrm{cB}$ & $11 \mathrm{bA}$ & $7 \mathrm{cC}$ & $8 b B$ & $10 \mathrm{bA}$ & $9 \mathrm{c}$ \\
\hline \multirow[t]{2}{*}{ Média } & $12 \mathrm{C}$ & $14 \mathrm{~A}$ & $11 \mathrm{D}$ & $12 \mathrm{C}$ & $13 \mathrm{~B}$ & - \\
\hline & \multicolumn{6}{|c|}{ Espiguetas (n. ${ }^{o}$ panícula $\left.{ }^{-1}\right)$} \\
\hline Alta & $66 \mathrm{aAB}$ & $69 \mathrm{aA}$ & $70 \mathrm{aA}$ & $63 \mathrm{bAB}$ & $58 \mathrm{bC}$ & $65 \mathrm{a}$ \\
\hline Média & $70 \mathrm{aAB}$ & $69 \mathrm{aAB}$ & $61 \mathrm{bB}$ & $75 \mathrm{aA}$ & $75 \mathrm{aA}$ & $70 \mathrm{a}$ \\
\hline Baixa & $75 \mathrm{aA}$ & $65 \mathrm{aB}$ & $72 \mathrm{aAB}$ & $75 \mathrm{aA}$ & $74 \mathrm{aA}$ & $72 \mathrm{a}$ \\
\hline \multirow[t]{2}{*}{ Média } & $70 \mathrm{~A}$ & $68 \mathrm{~A}$ & $68 \mathrm{~A}$ & $71 \mathrm{~A}$ & $69 \mathrm{~A}$ & - \\
\hline & \multicolumn{6}{|c|}{ Fertilidade das espiguetas (\%) } \\
\hline Alta & $62 \mathrm{aA}$ & $60 \mathrm{bA}$ & $55 \mathrm{bA}$ & $55 \mathrm{bA}$ & $55 \mathrm{aA}$ & $57,8 \mathrm{~b}$ \\
\hline Média & $65 \mathrm{aA}$ & $60 \mathrm{bA}$ & $66 \mathrm{bA}$ & $66 \mathrm{bA}$ & $58 \mathrm{aA}$ & $60,8 b$ \\
\hline Baixa & $72 \mathrm{aAB}$ & $83 \mathrm{aA}$ & $83 \mathrm{aA}$ & $83 \mathrm{aA}$ & $65 \mathrm{aB}$ & $73,0 \mathrm{a}$ \\
\hline \multirow[t]{2}{*}{ Média } & $66 \mathrm{~A}$ & $68 \mathrm{~A}$ & $68 \mathrm{~A}$ & $67 \mathrm{~A}$ & $59 \mathrm{~B}$ & - \\
\hline & \multicolumn{6}{|c|}{ Peso de 100 grãos (gramas) } \\
\hline Alta & $2,6 \mathrm{aABC}$ & $2,4 \mathrm{aBC}$ & $2,1 \mathrm{aC}$ & $2,8 \mathrm{aAB}$ & $2,9 \mathrm{aA}$ & $2,6 \mathrm{a}$ \\
\hline Média & $2,3 \mathrm{aA}$ & $2,3 \mathrm{aA}$ & $2,5 \mathrm{aA}$ & $2,5 \mathrm{aA}$ & $2,2 \mathrm{bA}$ & $2,4 \mathrm{a}$ \\
\hline Baixa & $2,5 \mathrm{aA}$ & $2,6 \mathrm{aA}$ & $2,6 \mathrm{aA}$ & $2,4 \mathrm{aA}$ & $2,5 \mathrm{abA}$ & $2,5 \mathrm{a}$ \\
\hline \multirow[t]{2}{*}{ Média } & $2,5 \mathrm{~A}$ & $2,4 \mathrm{~A}$ & $2,4 \mathrm{~A}$ & $2,6 \mathrm{~A}$ & $2,5 \mathrm{~A}$ & - \\
\hline & \multicolumn{6}{|c|}{ Produtividade de grãos (g planta $\left.{ }^{-1}\right)$} \\
\hline Alta & $12 \mathrm{aA}$ & $12 \mathrm{aA}$ & $13 \mathrm{aA}$ & $13 \mathrm{bA}$ & $13 \mathrm{aA}$ & $12,6 b$ \\
\hline Média & $14 \mathrm{aB}$ & $13 \mathrm{aB}$ & $13 \mathrm{aB}$ & $18 \mathrm{aA}$ & $12 \mathrm{aB}$ & $14,0 \mathrm{a}$ \\
\hline Baixa & $12 \mathrm{aA}$ & $11 \mathrm{aA}$ & $13 \mathrm{aA}$ & $12 \mathrm{bA}$ & $12 \mathrm{aA}$ & $12,0 \mathrm{~b}$ \\
\hline Média & $13 \mathrm{AB}$ & $12 \mathrm{~B}$ & $13 \mathrm{AB}$ & $14 \mathrm{~A}$ & $12 \mathrm{~B}$ & - \\
\hline
\end{tabular}

${ }^{1} \mathrm{CQT}: \mathrm{Zn}+\mathrm{Fe}+\mathrm{Mn}$. Médias com a mesma letra, minúsculas nas colunas e maiúsculas nas linhas não diferem pelo teste LSD $(\mathrm{p} \leq 0,05)$.

Fonte: Elaboração dos autores.

A produtividade de grãos por planta foi pouco influenciada pelos níveis de acidez do solo (Tabela 9), sendo que, observou-se maior produtividade na acidez média ( $\mathrm{pH}$ 5,5) somente com a aplicação de
Mn. Com o desdobramento dos micronutrientes em cada nível de acidez, observou-se que para baixa e alta acidez não houve diferença. A razão para a maior produtividade de grãos com aplicação de Mn, 
pode ser devido a elevação do $\mathrm{pH}$ do solo reduzir a disponibilidade de alguns nutrientes (Tabela 1), como o Mn (MALAVOLTA, 1980; SORATTO; CRUSCIOL, 2008) e o seu fornecimento via adubação suprir a planta. Quando a acidez passou de alta à média, a adição de Mn foi essencial para o aumento da produtividade de grãos. Observou-se também que essa cultivar parece não ser tolerante a alta acidez do solo ( $\mathrm{pH} 4,5)$ e, também, a baixa acidez (pH 6,3), devido a redução na disponibilidade de amônio (Tabela 2), Cu (Tabela 4), Zn (Tabela 5) e Mn (Tabela 7) e aumento na disponibilidade de nitrato (Tabela 2), pois causou reduções significativas na cultura.

Dessa forma, pode-se observar que $\mathrm{pH}$ em torno de 5,5 foi o mais favorável à cultura do arroz, pois proporcionou valores médios de amônio (Tabela 2) e baixos de nitrato (Tabela 3). Esses resultados corroboram com os de Araújo (2005) que relatou que o arroz possui melhor desenvolvimento em ambientes com maiores quantidade de nitrogênio no solo na forma de amônio em relação ao nitrato. No entanto, apesar da importância do $\mathrm{N}$ na forma amoniacal para o arroz, ambiente somente com essa forma de $\mathrm{N}$ também pode ser prejudicial à cultura (LIN et al., 2005; LI et al., 2007; POLETTO et al., 2011).

\section{Conclusões}

A adição de micronutrientes não afeta os teores de amônio e nitrato no solo;

Aacidez do solo afeta significativamente os teores de nitrato e amônio no solo, o teor de micronutrientes pelas plantas de arroz, a produtividade da cultura e os componentes de produção;

A acidez média do solo ( $\mathrm{pH}$ 5,5) propicia teores médios a altos de $\mathrm{Cu}$ e Fe, médios de $\mathrm{Zn}$ e $\mathrm{Mn}$, alta atividade da enzima NR, resultando em maiores valores de matéria seca, perfilhos, panículas, espiguetas, peso de 100 grãos e consequentemente produtividade de grãos.

\section{Agradecimentos}

À FAPESP pelo financiamento da pesquisa e ao $\mathrm{CNPq}$ pela bolsa de produtividade em pesquisa concedida ao segundo, terceiro e sexto autores.

\section{Referências}

ARAÚJO, J. L. Atividade da redutase do nitrato sobre o crescimento e produção de grãos de arroz. 2005. Dissertação (Mestrado em Agronomia) - Universidade Federal de Lavras, Lavras.

BOUMAN, B. A. M.; FENG, L. P.; TUONG, T. P.; LU, G. A.; WANG, H. Q. Exploring options to grow rice using less water in northern China using a modeling approach II: Quantifying yield, water balance components, and water productivity. Agricultural Water Management, Amsterdam, v. 88, n. 1-3, p. 23-33, 2007.

CAIRES, E. F.; FONSECA, A. F. Absorção de nutrientes pela soja cultivada no sistema de plantio direto em função da calagem na superfície. Bragantia, Campinas, v. 59, n. 2, p. 213-220, 2000.

CAIRES, E. F.; FONSECA, A. F.; FFELDHAUS, I. C.; BLUM, J. Crescimento radicular e nutrição da soja cultivada no sistema plantio direto em resposta ao calcário e gesso na superfície. Revista Brasileira de Ciência do Solo, Viçosa, v. 25, n. 4, p. 1029-1040, 2001.

CRUSCIOL, C. A. C.; COSTA, A. M.; BORGHI, E.; CASTRO, G. S. A.; FERNANDES, D. M. Fertilizer distribution mechanisms and side dress nitrogen fertilization in upland rice under no-tillage system. Scientia Agricola, Piracicaba, v. 67, n. 5, p. 562-569, 2010.

CRUSCIOL, C. A. C.; GARCIA, R. A.; CASTRO, G. S. A.; ROSOLEM, C. A. Nitrate role in basic cation leaching under no-till. Revista Brasileira de Ciência do Solo, Viçosa, v. 35, n. 6, p. 1975-1984, 2011.

D’ANDRÉA, A. F.; SILVA, M. L. N.; CURI, N.; GUILHERME, L. R. G. Estoque de carbono e formas de nitrogênio mineral em solo submetido a diferentes sistemas de manejo. Pesquisa Agropecuária Brasileira, Brasília, v. 39, n. 2, p. 179-186, 2004.

EPSTEIN, E.; BLOOM, A. J. Nutrição mineral de plantas: princípios e perspectivas. Londrina: Planta, 2006. $86 \mathrm{p}$.

FAGERIA, N. K. Resposta de arroz de terras altas à correção de acidez em solo de cerrado. Pesquisa Agropecuária Brasileira, Brasília, v. 35, n. 11, p. 23032307, 2000. 
HAYATSU, M.; KOSUGE, N. Effects of urea fertilization and liming on nitrification in Cerrados soils (Brazil). Soil Science and Plant Nutrition, Tokyo, v. 39, n. 2, p. 367371, 1993.

JAWORSKI, E. G. Nitrate reductase assay in intact plant tissues. Biochemical and Biophysical Research Communications, Easton, v. 43, n. 6, p. 1274-1279, 1971.

KIRKBY, E. A.; RÖMHELD, V. Micronutrientes na fisiologia de plantas: funções, absorção e mobilidade. Informações Agronômicas, n. 118, p. 1-24, 2007.

KLUTHCOUSKI, J.; FANCELLI, A. L.; DOURADO NETO, D.; RIBEIRO, C. M.; FERRARO, L. A. Manejo do solo e o rendimento de soja, milho, feijão e arroz em plantio direto. Scientia Agricola, Piracicaba, v. 57, n. 1, p. $97-104,2000$.

KORNDÖRFER, G. H.; ARANTES, V. A.; CORREA, G. F.; SNYDER, G. H. Efeito do silicato de cálcio no teor de silício no solo e na produção de grãos de arroz de sequeiro. Revista Brasileira de Ciência do Solo, Viçosa, v. 23, n. 3, p. 623-629, 1999.

LI, Y. L.; ZHANG, Y. L.; HU, J.; SHEN, Q. R. Contribution of nitrification happened in rhizospheric soil growing with different rice cultivars to $\mathrm{N}$ nutrition. Biology and Fertility of Soils, Berlin, v. 43, n. 4, p. 417425, 2007.

LIN, S.; LI, J.; SATTELMACHER, B.; BRÜCK, H. Response of lowland and aerobic rice to ammonium and nitrate supply during early growth stages. Journal of Plant Nutrition, New York, v. 28, n. 9, p. 1495-1510, 2005.

MALAVOLTA, E. Elementos de nutrição mineral de plantas. São Paulo: Agronômica Ceres, 1980. 251 p.

MALAVOLTA, E.; VITTI, G. C.; OLIVEIRA, S. A. Avaliação do estado nutricional de plantas: princípios e aplicações. 2. ed. Piracicaba: Potafos, 1997. 319 p.

MAUAD, M.; CRUSCIOL, C. A. C.; GRASSI FILHO, H. Produção de massa seca e nutrição de cultivares de arroz de terras altas sob condição de déficit hídrico e adubação silicatada. Semina: Ciências Agrárias, Londrina, v. 32, n. 3, p. 939-948, 2011.

MOREIRA, A.; GARCIA, A. L. G.; HEINRICHS, R.; MALAVOLTA, E. Influência do magnésio, boro e manganês na absorção de zinco por raízes destacadas de duas cultivares de arroz. Semina: Ciências Agrárias, Londrina, v. 24, n. 2, p. 213-218, 2003.

NASCENTE, A. S.; GUIMARÃES, C. M.; COBUCCI, T.; CRUSCIOL, C. A. C. Brachiaria ruziziensis and herbicide on yield of upland rice. Planta Daninha, Viçosa, v. 30, n. 4, p. 729-735, 2012.
NASCENTE, A. S.; KLUTHKOUSKI, J.; RABELO, R. R.; OLIVEIRA, P.; COBUCCI, T.; CRUSCIOL, C. A. C. Produtividade do arroz de terras altas em função do manejo do solo e da época de aplicação de nitrogênio. Pesquisa Agropecuária Tropical, Goiânia, v. 41, n. 1, p. 60-65, 2011a.

NASCENTE, A. S.; KLUTHKOUSKI, J.; RABELO, R. R.; OLIVEIRA, P.; COBUCCI, T.; CRUSCIOL, C. A. C. Desenvolvimento e produtividade de cultivares de arroz de terras altas em função do manejo do solo. Pesquisa Agropecuária Tropical, Goiânia, v. 41, n. 2, p. 189-192, $2011 b$.

POLETTO, N.; MUNDSTOCK, C. M.; GROHS, D. S.; MAZURANA, M. Padrão de afilhamento em arroz afetado pela presença dos íons amônio e nitrato. Bragantia, Campinas, v. 70, n. 1, p. 96-103, 2011.

RAIJ, B.; ANDRADE, J. C.; CANTARELLA, H.; QUAGGIO, J. A. Análise química para avaliação da fertilidade de solos tropicais. Campinas: Instituto Agronômico, 2001. 285 p.

RAIJ, B.; CANTARELLA, H.; QUAGGIO, J. A.; FURLANI, A. M. C. Recomendações de adubação e calagem para o Estado de São Paulo. 2. ed. Campinas: Instituto Agronômico de Campinas, 1996. 285 p.

SANTOS, A. M.; BUCHER, C. A.; STARK, E. M. L. M.; FERNANDES, M. S.; SOUZA, S. R. Efeito da disponibilidade de nitrato em solução nutritiva sobre a absorção de nitrogênio e atividade enzimática de duas cultivares de arroz. Bragantia. Campinas, v. 68 , n. 1, p. 215-220, 2009.

SILVA, F. C. Manual de análises químicas de solos, plantas e fertilizantes. Rio de Janeiro: Embrapa Solos, 1999. $370 \mathrm{p}$.

SORATTO, R. P.; CRUSCIOL, C. A. C. Dolomite and phosphogypsum surface application effects on annual crops nutrition and yield. Agronomy Journal, Madison, v. 100, n. 2, p. 261-270, 2008.

TA, T. C.; OHIRA, K. Effects of various environmental and medium conditions on the response of Indica and Japonica rice plants to ammonium and nitrate nitrogen. Soil Science and Plant Nutrition, Tokyo, v. 27, n. 3, p. 347 355, 1981.

TISDALE, S. I.; NELSON, W. I.; BEATON, J. D. Soil fertility and fertilizers. 4. ed. New York: Macmillan, $1985.754 \mathrm{p}$. 